\title{
Prognostic significance of tumor genotypes and CD8+ infiltrates in stage I-III colorectal cancer
}

\author{
Elena Fountzilas ${ }^{1}$, Vassiliki Kotoula2,3, Ioannis Tikas ${ }^{3}$, Kyriaki Manousou ${ }^{4}$, Kyriaki \\ Papadopoulou $^{3}$, Christos Poulios ${ }^{2}$, Vasilios Karavasilis ${ }^{5}$, Ioannis Efstratiou ${ }^{6}$, Dimitrios \\ Pectasides $^{7}, K^{\prime}$ leo Papaparaskeva ${ }^{8}$, Ioannis Varthalitis ${ }^{9}$, Christos Christodoulou ${ }^{10}$, \\ George Papatsibas ${ }^{11}$, Sofia Chrisafi ${ }^{3}$, Georgios K. Glantzounis ${ }^{12}$, Amanda Psyrri ${ }^{13}$, \\ Gerasimos Aravantinos ${ }^{14}$, Georgia-Angeliki Koliou ${ }^{4}$, George K. Koukoulis ${ }^{15}$, George \\ E. Pentheroudakis ${ }^{16}$ and George Fountzilas ${ }^{3,17}$ \\ ${ }^{1}$ Department of Investigational Cancer Therapeutics, University of Texas MD Anderson Cancer Center, Houston, Texas, USA \\ ${ }^{2}$ Department of Pathology, Faculty of Medicine, School of Health Sciences, Aristotle University of Thessaloniki, Thessaloniki, \\ Greece \\ ${ }^{3}$ Laboratory of Molecular Oncology, Hellenic Foundation for Cancer Research/Aristotle University of Thessaloniki, Thessaloniki, \\ Greece \\ ${ }^{4}$ Section of Biostatistics, Hellenic Cooperative Oncology Group, Athens, Greece \\ ${ }^{5}$ Department of Medical Oncology, Papageorgiou Hospital, Faculty of Medicine, School of Health Sciences, Aristotle University \\ of Thessaloniki, Thessaloniki, Greece \\ ${ }^{6}$ Department of Pathology, Papageorgiou Hospital, Thessaloniki, Greece \\ ${ }^{7}$ Oncology Section, Second Department of Internal Medicine, Hippokration Hospital, Athens, Greece \\ ${ }^{8}$ Department of Pathology, Konstantopouleio Agia Olga General Hospital, Athens, Greece \\ ${ }^{9}$ Oncology Department, General Hospital of Chania, Crete, Greece \\ ${ }^{10}$ Second Department of Medical Oncology, Metropolitan Hospital, Piraeus, Greece \\ ${ }^{11}$ Oncology Department, University General Hospital of Larissa, Larissa, Greece \\ ${ }^{12}$ Department of Surgery, University Hospital of Ioannina and School of Medicine, University of Ioannina, Greece \\ ${ }^{13}$ Division of Oncology, Second Department of Internal Medicine, Attikon University Hospital, Athens, Greece \\ ${ }^{14}$ Second Department of Medical Oncology, Agii Anargiri Cancer Hospital, Athens, Greece \\ ${ }^{15}$ Department of Pathology, Faculty of Medicine, University of Thessaly, Larissa, Greece \\ ${ }^{16}$ Department of Medical Oncology, Ioannina University Hospital, Ioannina, Greece \\ ${ }^{17}$ Aristotle University of Thessaloniki, Thessaloniki, Greece
}

Correspondence to: Elena Fountzilas, email: elenafou@gmail.com

Keywords: targeted NGS; CD8; MMR; BRCA l; ARIDIA

Received: June 29, $2018 \quad$ Accepted: October 08, $2018 \quad$ Published: November 02, 2018

Copyright: Fountzilas et al. This is an open-access article distributed under the terms of the Creative Commons Attribution License 3.0 (CC BY 3.0), which permits unrestricted use, distribution, and reproduction in any medium, provided the original author and source are credited.

\section{ABSTRACT}

Background: We explored the clinical significance of tumor genotypes and immunophenotypes in non-metastatic colorectal cancer (CRC).

Methods: In primary tumors (paraffin blocks) from 412 CRC patients treated with adjuvant chemotherapy, we examined pathogenic mutations (panel NGS; 347 informative); mismatch repair (MMR) immunophenotype (360 informative); and CD8+ lymphocyte density (high - low; 412 informative). The primary outcome measure was disease-free survival (DFS).

Results: We evaluated 1713 pathogenic mutations (median: 3 per tumor; range 0-49); 118/412 (28.6\%) tumors exhibited high CD8+ density; and, 40/360 (11.1\%) were MMR-deficient. Compared to MMR-proficient, MMR-deficient tumors exhibited 
higher CD8+ density (chi-square, $\mathrm{p}<\mathbf{0 . 0 0 1}$ ) and higher pathogenic mutation numbers $(p=0.003)$. High CD8+ density was an independent favorable prognosticator $(H R=0.49$, 95\%CI 0.29-0.84, Wald's $p=0.010)$. Pathogenic BRCA1 and ARID1A mutations were inversely associated with each other $(p<0.001)$, were not associated with MMRdeficiency or CD8+ density, but both independently predicted for unfavorable DFS $(H R=1.98,95 \% C I 1.12-3.48, p=0.018$ and $H R=1.99,95 \% C I 1.11-3.54, p=0.020$, respectively).

Conclusion: In non-metastatic CRC, high CD8+ lymphocyte density confers a favorable prognosis and may be developed as a single marker in routine diagnostics. The unfavorable prognostic effect of pathogenic BRCA1 and ARID1A mutations is a novel observation that, if further validated, may improve treatment selection.

\section{INTRODUCTION}

During the past decades, the heterogeneity of colorectal cancer (CRC) has become evident [1]. Recently, an international consortium showed that there is significant prognostic variability associated with specific tumor characteristics in colorectal cancer [2]. The revelation of clinically significant, biological characteristics of $\mathrm{CRC}$ has become a priority.

Tumor genotypic characteristics have been extensively studied with respect to clinical and pathological tumor heterogeneity and prognosis in patients with metastatic CRC [3-5]. However, their prognostic significance in non-metastatic CRC remains controversial [6-9]. Increasing evidence also suggest that the local adaptive immune response plays a central role in disease recurrence and overall survival (OS) of patients with CRC $[10,11]$. There is a need to map the non-metastatic $\mathrm{CRC}$ oncogenic mutational and immunophenotypic landscape to accurately stratify patients. The "one-sizefits-all" approach needs to be replaced by personalized management based on the specific molecular alterations of each tumor in early-stage disease.

Our goal was to explore clinicopathological and prognostic significance of tumor molecular alterations and CD8+ lymphocyte density and identify clinically relevant biomarkers in patients with stage I-III CRC. We used targeted next-generation sequencing and immunophenotyping of colorectal tumors to identify clinically relevant genotypic and phenotypic tumor characteristics and assess their associations with patient outcomes.

\section{RESULTS}

\section{Clinicopathological characteristics}

Our study included 412 patients with colorectal cancer, 229 men and 183 women. Median age was 65 years. Based on the histological report, $20 \%$ of the tumors were grade 3. The distribution of TNM stage was: $3.7 \%$ stage I, $33.4 \%$ stage II and $62.9 \%$ stage III. Perineural (PNI) and/or lymphovascular (LVI) invasion was noted in $35 \%$ of the tumors. R1 resection (microscopic residual tumor) or $\mathrm{R} 2$ resection (macroscopic residual tumor) was reported in 3 of 341 patients $(0.8 \%)$. All patients received adjuvant treatment with chemotherapy, with a median of 8 cycles with or without radiation therapy.

Detailed clinicopathological characteristics are reported in Table 1.

Tumors were located at the right colon (139, $34 \%)$, left colon $(171,41 \%)$ or rectum $(102,25 \%)$. Stage distribution (I, II, III) did not differ between the different tumor locations (chi-square $\mathrm{p}=0.937$ ). A significant association was observed between tumor location and grade (chi-square $\mathrm{p}=0.001$ ), with right-sided tumors being more frequently high-grade $(30.6 \%)$ compared to leftsided $(17.5 \%)$ or rectal tumors $(9.1 \%)$.

\section{Mismatch repair (MMR) immunohistochemistry (IHC) status and immune cell infiltrates}

The distribution of IHC parameters in the entire cohort and by tumor location are presented in Table 2 . Among the 360 tumors with informative MMR IHC status, 40 exhibited MMR deficiency (MMR-D, 11.1\%). MMR-D was significantly more frequent in right-sided tumors (25.8\%) compared to left-sided (4\%) and rectal tumors (3.3\%) (chi-square, $\mathrm{p}<0.001$ ). In comparison to MMRproficiency (MMR-P), MMR-D was associated with younger age (Mann-Whitney $\mathrm{p}=0.010$ ); higher histological grade; grade 3 in $42.1 \%$ MMR-D and $17.2 \%$ in MMR-P tumors (chi square $\mathrm{p}<0.001$ ), and lower disease stage; stage III was diagnosed in $47.2 \%$ patients with MMR-D compared to $64.6 \%$ patients with MMR-P tumors (chisquare, $\mathrm{p}=0.041$ ). The distribution of clinicopathological characteristics according to tumor MMR status is shown in Supplementary Table 1.

We also assessed the density of CD8+ cells in the tumor center and front, distinguishing for $\mathrm{CD} 8+$ in the tumor stroma (stromal) and within cancer cell nests, in direct contact to cancer cells (intratumoral). However, as described in detail in Methods, we finally evaluated the combined presence of CD8+ independently of tumor compartment as "high", if stromal and intratumoral CD8+ density were above the corresponding cut-offs for each architectural compartment; and "other" for all other combinations. A significant association was observed 
Table 1: Clinicopathological characteristics in the entire cohort and by tumor location (right colon, left colon, rectum)

\begin{tabular}{|c|c|c|c|c|c|}
\hline Parameter & $\begin{array}{l}\text { Entire cohort } \\
\quad(n=412)\end{array}$ & $\begin{array}{l}\text { Right colon } \\
\quad(n=139)\end{array}$ & $\begin{array}{c}\text { Left colon } \\
(n=171)\end{array}$ & Rectum $(n=102)$ & p-value \\
\hline Age & & & & & 0.15 \\
\hline Mean +/- SD & $63.1+/-10.7$ & $63.5+/-10.9$ & $63.8+/-10.5$ & $61.5+/-10.7$ & \\
\hline Median (IQR) & $65.3(56.5,71.6)$ & $64.9(56.1,72.3)$ & $66.3(57.1,72.0)$ & $63.0(53.4,70.1)$ & \\
\hline Min-Max & $28-81$ & $28-80$ & $28-81$ & $28-79$ & \\
\hline Gender & & & & & 0.953 \\
\hline Female & $183(44.4 \%)$ & $62(44.6 \%)$ & $77(45.0 \%)$ & $44(43.1 \%)$ & \\
\hline Male & $229(55.6 \%)$ & $77(55.4 \%)$ & $94(55.0 \%)$ & $58(56.9 \%)$ & \\
\hline Tumor location & & & & & $\mathrm{N} / \mathrm{A}$ \\
\hline Ascending & $62(15.1 \%)$ & $62(44.9 \%)$ & 0 & 0 & \\
\hline Cecum & $48(11.7 \%)$ & $48(34.8 \%)$ & 0 & 0 & \\
\hline Cecum (multifocal) & $2(0.5 \%)$ & $2(1.4 \%)$ & 0 & 0 & \\
\hline Descending & $16(3.9 \%)$ & 0 & $16(9.4 \%)$ & 0 & \\
\hline Hepatic flexure & $10(2.4 \%)$ & $10(7.2 \%)$ & 0 & 0 & \\
\hline Rectosigmoid & $8(1.9 \%)$ & 0 & $8(4.7 \%)$ & 0 & \\
\hline Rectum & $102(24.9 \%)$ & 0 & 0 & $102(100.0 \%)$ & \\
\hline Sigmoid & $138(33.7 \%)$ & 0 & $138(81.2 \%)$ & 0 & \\
\hline Splenic flexure & $8(2 \%)$ & 0 & $8(4.7 \%)$ & 0 & \\
\hline Transverse & $16(3.9 \%)$ & $16(11.6 \%)$ & $0(0 \%)$ & 0 & \\
\hline Missing & 2 & & & & \\
\hline Perforation & & & & & 0.017 \\
\hline No & $375(96.4 \%)$ & $129(98.5 \%)$ & $151(93.2 \%)$ & $95(99.0 \%)$ & \\
\hline Yes & $14(3.6 \%)$ & $2(1.5 \%)$ & $11(6.8 \%)$ & $1(1.0 \%)$ & \\
\hline Missing & 23 & & & & \\
\hline Obstruction & & & & & 0.015 \\
\hline No & $345(88.5 \%)$ & $118(90.1 \%)$ & $135(83.3 \%)$ & $92(94.8 \%)$ & \\
\hline Yes & $45(11.5 \%)$ & $13(9.9 \%)$ & $27(16.7 \%)$ & $5(5.2 \%)$ & \\
\hline Missing & 22 & & & & \\
\hline Primary tumor $(\mathrm{T})$ & & & & & N/A \\
\hline $\mathrm{T} 1$ & $4(1.0 \%)$ & 0 & $2(1.2 \%)$ & $2(2.0 \%)$ & \\
\hline $\mathrm{T} 2$ & $35(8.5 \%)$ & $8(5.8 \%)$ & $12(7.1 \%)$ & $15(15.0 \%)$ & \\
\hline $\mathrm{T} 3$ & $329(79.9 \%)$ & $117(84.2 \%)$ & $136(80.0 \%)$ & $76(76.0 \%)$ & \\
\hline $\mathrm{T} 4$ & $41(10.0 \%)$ & $14(10.1 \%)$ & $20(11.8 \%)$ & $7(7.0 \%)$ & \\
\hline Missing & 3 & & & & \\
\hline Regional lymph nodes (N) & & & & & 0.542 \\
\hline No & $153(37.5 \%)$ & $56(40.3 \%)$ & $60(35.7 \%)$ & $37(36.6 \%)$ & \\
\hline N1 & $176(43.1 \%)$ & $56(40.3 \%)$ & $71(42.3 \%)$ & $49(48.5 \%)$ & \\
\hline
\end{tabular}

(Continued) 


Parameter

$\mathrm{N} 2$

Missing

Stage, detailed categories

I

IIA

IIB

IIIA

IIIB

IIIC

Missing

\section{Grade}

1

2

3

Missing

Mucinous component

$$
\text { No }
$$

Yes

Missing

\section{Perineural invasion}

$$
\text { No }
$$

Yes

Missing

Lympatic vessel invasion

No

Yes

Missing

Blood vessel invasion

No

Yes

Missing

Treatment

Capecitabine

FOLFOX

CAPOX

Missing

\section{Entire cohort $(n=412)$}

$79(19.4 \%)$

4

$\begin{array}{cccc}15(3.7 \%) & 6(4.3 \%) & 6(3.5 \%) & 3(3.0 \%) \\ 122(29.7 \%) & 43(30.9 \%) & 46(27.1 \%) & 33(32.7 \%) \\ 15(3.7 \%) & 6(4.3 \%) & 8(4.7 \%) & 1(1.0 \%) \\ 27(6.6 \%) & 6(4.3 \%) & 10(5.9 \%) & 11(10.9 \%) \\ 153(37.3 \%) & 52(37.4 \%) & 63(37.1 \%) & 38(37.6 \%) \\ 78(19.0 \%) & 26(18.7 \%) & 37(21.8 \%) & 15(14.9 \%)\end{array}$

2

$21(5.3 \%)$
$299(74.9 \%)$
$79(19.8 \%)$
13

$7(5.2 \%)$

$86(64.2 \%)$

$41(30.6 \%)$

13

$$
\begin{gathered}
273(72.8 \%) \\
102(27.2 \%) \\
37
\end{gathered}
$$

\section{7}

$$
84(67.2 \%)
$$

$41(32.8 \%)$

\section{$328(84.6 \%)$}

$59(15.4 \%)$

$110(87.3 \%)$

$16(12.7 \%)$

25

$$
\begin{gathered}
298(77.0 \%) \\
89(23.0 \%) \\
25
\end{gathered}
$$$$
92(73.0 \%)
$$$$
34(27.0 \%)
$$

$$
\begin{gathered}
332(86.0 \%) \\
54(14.0 \%) \\
26
\end{gathered}
$$$$
109(86.5 \%)
$$$$
17(13.5 \%)
$$

$$
\begin{gathered}
1(0.2 \%) \\
137(33.6 \%) \\
270(66.2 \%) \\
4
\end{gathered}
$$

$120(76.4 \%)$

$69(74.2 \%)$

$135(82.8 \%)$

$28(17.2 \%)$

$83(84.7 \%)$

$129(79.1 \%)$

77 (78.6\%)

$136(84.0 \%)$

$26(16.0 \%)$

$87(88.8 \%)$

N/A

0.001

$$
0.21
$$

$0.238^{*}$

$\begin{array}{ccc}0 & 0 & 1(1.0 \%) \\ (29.0 \%) & 64(38.1 \%) & 33(32.4 \%) \\ (71.0 \%) & 104(61.9 \%) & 68(66.7 \%)\end{array}$

(Continued) 


\begin{tabular}{lccccc}
\hline Parameter & $\begin{array}{c}\text { Entire cohort } \\
(\mathbf{n = 4 1 2})\end{array}$ & $\begin{array}{c}\text { Right colon } \\
(\mathbf{n = 1 3 9})\end{array}$ & $\begin{array}{c}\text { Left colon } \\
(\mathbf{n = 1 7 1})\end{array}$ & Rectum (n=102) & p-value \\
\hline Radiation therapy & & & & & N/A \\
No & $279(76.9 \%)$ & $119(99.2 \%)$ & $147(97.4 \%)$ & $13(14.1 \%)$ & \\
Yes & $84(23.1 \%)$ & $1(0.8 \%)$ & $4(2.6 \%)$ & $79(85.9 \%)$ & \\
Missing & 49 & & & & \\
\hline
\end{tabular}

${ }^{*} 1$ patient with Capecitabine was excluded from the estimation of p-value.

Abbreviations: IQR: interquartile range, LVI: lymphovascular invasion, n: number, No: number, N/A: not applicable, PNI: perineural invasion, PS: performance status, SD: standard deviation.

between CD8+ density and tumor location. Right-sided tumors more frequently had high CD8+ density compared to the other tumor sites (CD8+ high: right-sided $41 \%$, leftsided $19 \%$ and rectal tumors $28 \%$, chi-square, $\mathrm{p}<0.001$ ) (Table 2).

In comparison to MMR-P tumors, MMR-D tumors were more likely to exhibit high CD8+ density $(65 \%$ in MMR-D vs. $27 \%$ in MMR-P, chi-square, $\mathrm{p}<0.001$ ). Details are shown in Supplementary Table 1.

\section{NGS results}

We identified a total of 5239 mutations in 55 genes distributed in 339 out of 347 NGS informative tumors (median 4; range $1-220$; mean \pm SD 15 \pm 36 ). Out of all mutations, in the same genes, 1713 were pathogenic and were found in 332/347 (95.7\%) tumors. The median number of pathogenic mutations per tumor was 3 (range, 1-49 mutations). The median number of genes with pathogenic mutations per tumor was 3 (range, 1-28 genes). Tumors without mutations $(\mathrm{N}=8)$ and without pathogenic mutations $(\mathrm{N}=15)$ in the panel genes were considered as true negatives, based on their sequencing characteristics (Supplementary Figure 1). The median number of mutations, pathogenic mutations and mutated genes per tumor did not differ between tumor locations (Mann-Whitney, $\mathrm{p}=0.460, \mathrm{p}=0.520, \mathrm{p}=0.620$, respectively).

The distribution and characteristics of mutations are shown in Figure 2A, and the prevalence of pathogenic mutations in Figure 2B. Among the 347 tumors, pathogenic mutations most frequently concerned APC (56\%), TP53 (55\%), KRAS (48\%), PIK3CA (18\%), and BRCA1 (13\%). BRAF mutations were present in 26/347 tumors (7.5\%) (Figure 2B); 21 had the classic p.Val600Glu (p.V600E); 4 had non-V600E mutations; and, 1 tumor had p.Val600Glu and p.Ala598Thr at respective variant allelic frequencies (VAFs) of $16 \%$ and $10 \%$ in a sample with 50\% tumor cell DNA (Supplementary Table 2). Mutations in the 4 MMR genes encoding the proteins assessed by IHC (MLH1, PMS2, MSH2, MSH6) were identified in 22 tumors (6.3\%). MMR gene mutations and IHC MMR status was comparable in 17 tumors. MMR-D was observed in only 4 of these tumors, including one case with double MLH1 and MSH2 protein loss and corresponding mutations; the remaining 13 tumors with MMR gene mutations were characterized as MMR-P with IHC (Supplementary Table 3).

\section{Associations between mutations and clinicopathological parameters}

A significantly higher number of total mutations was noted in MMR-D compared to MMR-P tumors (MannWhitney $\mathrm{p}=0.003$ ) (Figure 2C, Supplementary Table 1). However, compared to tumors identified as MMR-D with IHC, MMR-P tumors with MMR gene mutations in fact exhibited significantly higher numbers of mutations (Mann-Whitney $\mathrm{p}<0.0001$; Figure $2 \mathrm{C}$ ), were preferentially left sided (11/13 tumors; chi-square $\mathrm{p}<0.0001)$; exhibited different patterns of coexisting clonal pathogenic mutations, e.g., a higher incidence in POLE (Fisher's exact $\mathrm{p}=0.0002$ ), and a lower incidence in the RAS/RAF pathways (Fisher's exact $\mathrm{p}=0.0155$ ) (Supplementary Table 3).

There was no association between mutations in the most frequently affected genes and CD8+ density. Most of the tumors with ATM $(p=0.043)$ and BRAF $(\mathrm{p}=0.015)$ mutations had high CD8+ but with one-sided significance.

BRAF and PIK3CA mutations were more frequently noted in right-sided compared to left-sided colon and rectal tumors (chi-square, $\mathrm{p}=0.020$ and $\mathrm{p}=0.018$, respectively). We observed a higher frequency of FBXW7 mutations in rectal tumors compared to the rest of the tumors (chi square, $\mathrm{p}=0.002$ ). Left-sided tumors had a higher TP53 mutation rate, compared to right-sided and rectal tumors (chi square, $\mathrm{p}=0.013$ ) (details in Table 2). RAS mutation rates did not differ among the tumors of the three anatomic locations (chi square, $p=694$ ).

Pathogenic BRCA1 and ARID1A mutations were inversely associated with each other $(\mathrm{p}<0.001)$. There were 46 patients with BRCA1 and 36 with ARID1A mutated tumors, equally distributed in right, left colon and rectum. Clonal mutations were present in 11 (24\%) of BRCA1 and in $16(44 \%)$ of ARID1 A mutated tumors, 
Table 2: IHC and NGS parameters in the entire cohort and by tumor location (right colon, left colon, rectum)

\begin{tabular}{|c|c|c|c|c|c|}
\hline Parameters ${ }^{*}$ & $\begin{array}{l}\text { Entire cohort } \\
\quad(n=412)\end{array}$ & $\begin{array}{l}\text { Right colon } \\
\quad(n=139)\end{array}$ & $\begin{array}{l}\text { Left colon } \\
(n=171)\end{array}$ & Rectum (n=102) & p-value \\
\hline & & & IHC & & \\
\hline MMR status & & & & & $<0.001$ \\
\hline Deficiency & $40(11.1 \%)$ & $31(25.8 \%)$ & $6(4.0 \%)$ & $3(3.3 \%)$ & \\
\hline Proficiency & $320(88.9 \%)$ & $89(74.2 \%)$ & $144(96.0 \%)$ & $87(96.7 \%)$ & \\
\hline Missing & 52 & & & & \\
\hline CD8+ density & & & & & $<0.001$ \\
\hline $\operatorname{High}^{\wedge}$ & $118(28.6 \%)$ & $57(41.0 \%)$ & $32(18.7 \%)$ & $29(28.4 \%)$ & \\
\hline \multirow[t]{2}{*}{ Other $^{\wedge}$} & $294(71.4 \%)$ & $82(59.0 \%)$ & $139(81.3 \%)$ & $73(71.6 \%)$ & \\
\hline & & & NGS & & \\
\hline BRAF & & & & & 0.020 \\
\hline No & $321(92.5 \%)$ & $99(86.8 \%)$ & $141(95.3 \%)$ & $81(95.3 \%)$ & \\
\hline Yes & $26(7.5 \%)$ & $15(13.2 \%)$ & $7(4.7 \%)$ & $4(4.7 \%)$ & \\
\hline TP53 & & & & & 0.013 \\
\hline No & $158(45.5 \%)$ & $61(53.5 \%)$ & $54(36.5 \%)$ & $43(50.6 \%)$ & \\
\hline Yes & $189(54.5 \%)$ & $53(46.5 \%)$ & $94(63.5 \%)$ & $42(49.4 \%)$ & \\
\hline FBXW7 & & & & & 0.002 \\
\hline No & $309(89.0 \%)$ & $104(91.2 \%)$ & $138(93.2 \%)$ & $67(78.8 \%)$ & \\
\hline Yes & $38(11.0 \%)$ & $10(8.8 \%)$ & $10(6.8 \%)$ & $18(21.2 \%)$ & \\
\hline PALB2 & & & & & 0.026 \\
\hline No & $321(92.5 \%)$ & $107(93.9 \%)$ & $141(95.3 \%)$ & $73(85.9 \%)$ & \\
\hline Yes & $26(7.5 \%)$ & $7(6.1 \%)$ & $7(4.7 \%)$ & $12(14.1 \%)$ & \\
\hline PIK3CA & & & & & 0.018 \\
\hline No & $284(81.8 \%)$ & $84(73.7 \%)$ & $129(87.2 \%)$ & $71(83.5 \%)$ & \\
\hline Yes & $63(18.2 \%)$ & $30(26.3 \%)$ & $19(12.8 \%)$ & $14(16.5 \%)$ & \\
\hline
\end{tabular}

* analysis was performed in informative samples.

Abbreviations: IHC: immunohistochemistry, IQR: interquartile range, MMR: mismatch repair, n: number, MUT: mutation, NGS: next-generation sequencing, N/A: not applicable, SD: standard deviation; ${ }^{\wedge}$ : High: high CD8+ density, stromal AND intratumoral (in direct contact with cancer cells); Other: only stromal high OR only intratumoral high OR none high.

while loss-of-heterozygosity inferred from the frequency of the mutated allele (see Supplementary Methods) was observed in 4 and 7 non-overlapping tumors, respectively. Mutations in BRCA1 and ARID1A were present in tumors with higher numbers of mutations and mutated genes (Mann-Whitney, p's $<0.001$ ). Mutations in these genes were mostly present in tumors without mutations in MMR genes (chi-square, p's <0.001), while ARID1A mutations were more frequent in tumors with a mucinous component (chi-square, $\mathrm{p}=0.005$ ) (Supplementary Table 4). There was no association betweenBRCA1 or ARID1A mutations with MMR-D or CD8+ high density.

\section{Patient outcomes}

During a median follow-up of 87.9 months (range 0.7-125.9), 113 disease-free survival (DFS) events occurred; median DFS was not reached. The effect of clinicopathological characteristics on DFS is presented in Supplementary Table 5. No significant difference in DFS was observed between patients treated with the two chemotherapy regimens (log-rank, $p=0.630$ ). Tumor location was not associated with DFS. Upon adjusting for clinicopathological parameters, stage, grade and LVI remained of independent prognostic significance (Supplementary Table 6). 
Detailed results of the univariate analysis of all study variables are shown in Supplementary Table 7. MMR-D did not appear to be prognostic in the entire cohort (HR=0.61, 95\% CI 0.29-1.25, Wald's $\mathrm{p}=0.170)$. However, MMR-D was found to be associated with improved DFS in the subgroup of patients with tumors located in the right colon, although the association was of marginal statistical significance $(\mathrm{HR}=0.36$, 95\% CI 0.13-1.04, Wald's $\mathrm{p}=0.058)$. High CD8+ density $(\mathrm{HR}=0.48,95 \%$ CI 0.29 0.77 , Wald's $p=0.003$ ) appeared to be favorably associated with DFS in the entire cohort (Figure 3A).

We did not identify any significant association between RAS mutational status and DFS. BRAF mutational status did not appear to be prognostic either in the entire cohort $(\mathrm{HR}=1.49,95 \%$ CI $0.77-2.88, \mathrm{p}=0.239)$ or in the subgroups of patients with MMR-D and MMR-P tumors $(\mathrm{HR}=2.63,95 \%$ CI $0.53-13.2, \mathrm{p}=0.240$ and $\mathrm{HR}=2.13$, 95\% CI 0.93-4.93, $\mathrm{p}=0.076$, respectively). Patients with BRAF non-V600E mutations had an excellent outcome, while the only patient with double
BRAF p.V600E and non-V600E experienced a relapse at 83 months. BRCA1 and ARID1A, were found to be prognostic in the entire cohort $(\mathrm{HR}=1.77,95 \% \mathrm{CI} 1.06-$ 2.97, $\mathrm{p}=0.030$ and $\mathrm{HR}=1.87,95 \%$ CI 1.07-3.25, $\mathrm{p}=0.028$, respectively) (Figure $3 \mathrm{~B}$ and $3 \mathrm{C}$ ). Multivariate analyses were performed in the entire cohort adjusting for tumor stage, grade and blood vessel invasion (Supplementary Table 7). High CD8+ density retained its favorable prognostic significance for DFS ( $\mathrm{HR}=0.49,95 \%$ CI 0.29 0.84, Wald's $\mathrm{p}=0.010$ ). BRCA1 and ARID1A mutations also retained their prognostic significance in multivariate analyses. The HR's for all relevant study parameters are depicted as a forest plot, in Figure 4.

\section{DISCUSSION}

We demonstrated that non-metastatic colorectal tumors have distinct clinicopathological, mutational and immunophenotypic profiles. We identified prognostic markers to aid in the stratification of non-metastatic

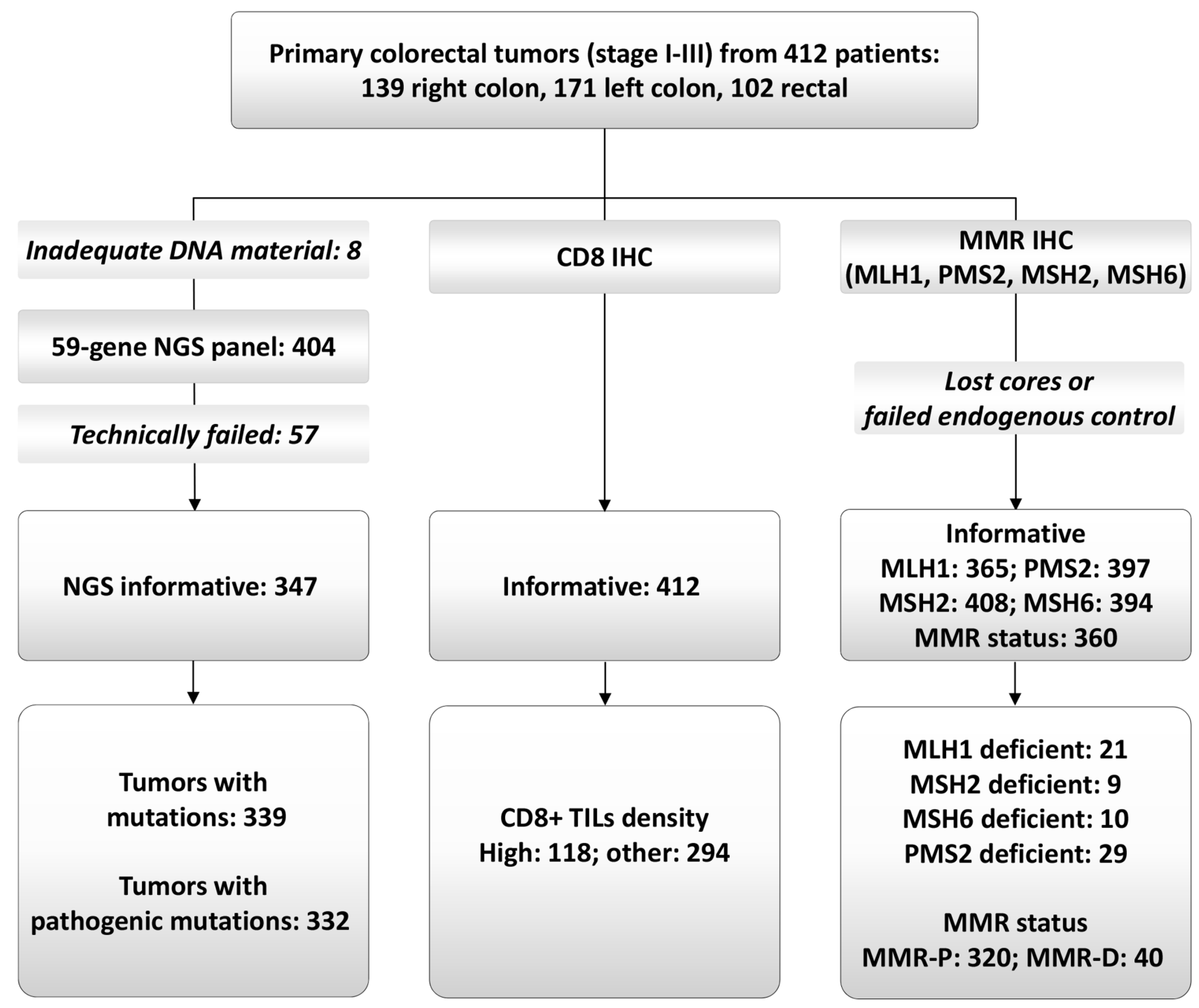

Figure 1: REMARK diagram. NGS: next generation sequencing; MMR: mismatch repair; MMR-P and MMR-D: proficient and deficient, respectively. 
A

Prevalence $(\%$ mutated tumors in total cohort $60 \quad 40 \quad 20$

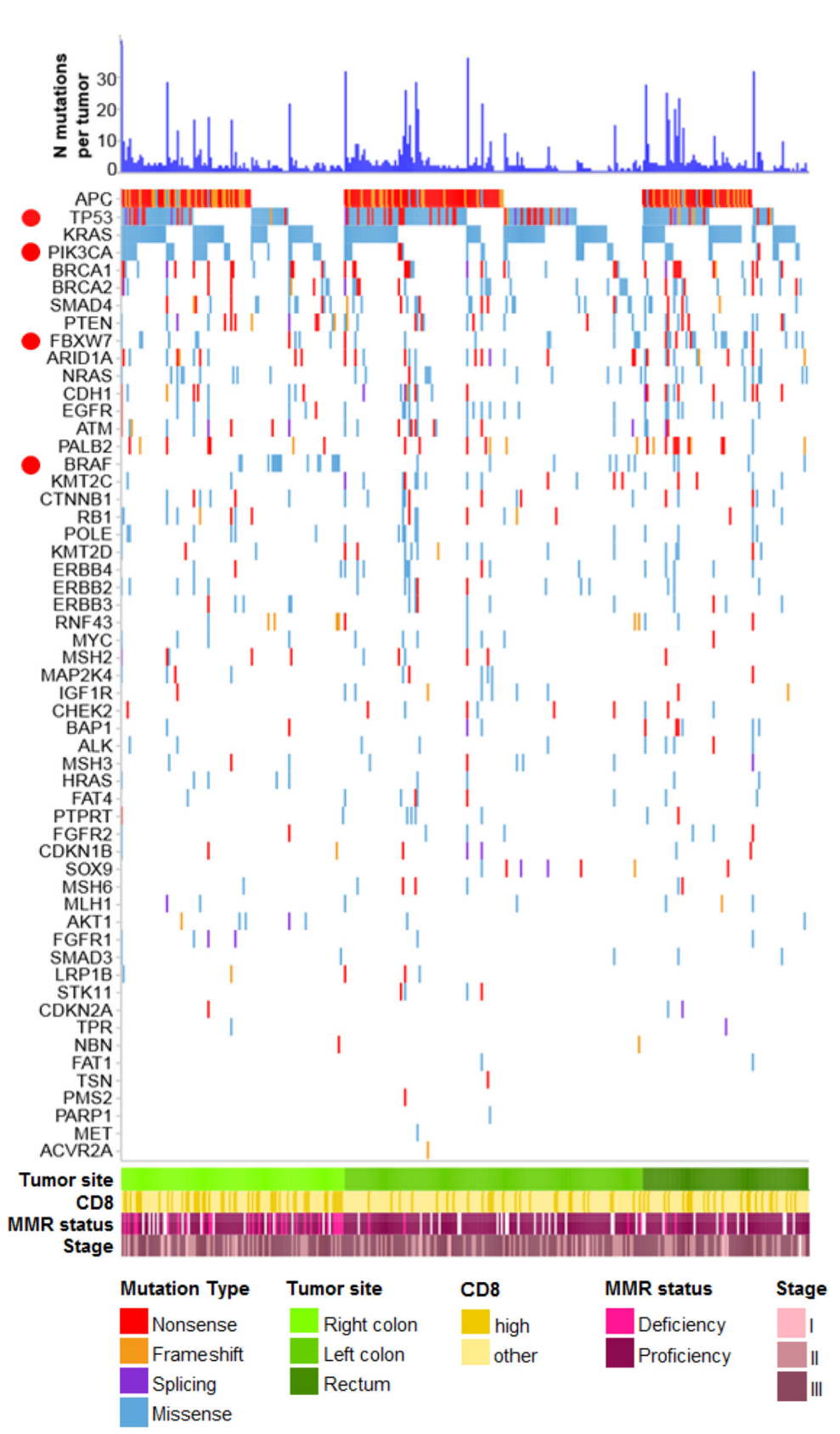

B

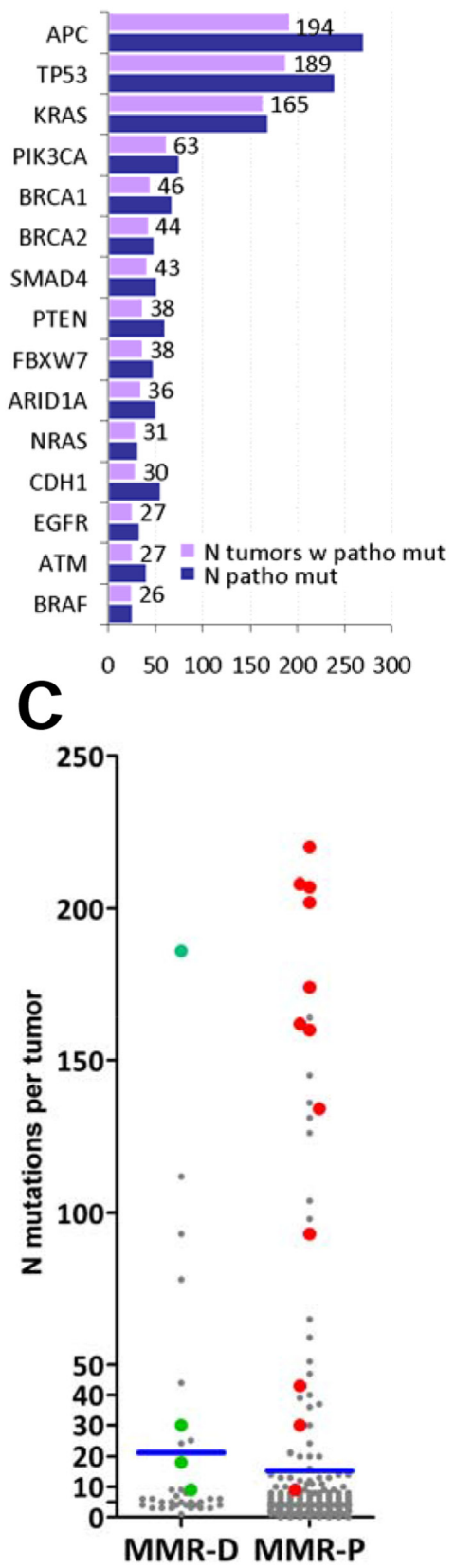

Figure 2: Map of pathogenic mutations in 332 CRC. (A) Out of 1713 pathogenic mutations, 32\% were nonsense or frameshifts in tumor suppressors, while missense mutations were dominant in known oncogenes. We did not apply the classification of hypermutated and non-hypermutated tumors because we used a 59-gene panel only. However, it is apparent that most tumors (75\%) carried more than 1 pathogenic mutation, the most frequent combination being APC \& TP53 in 1/3 of tumors, co-mutated with KRAS in $1 / 4$ of the cases, while $10 \%$ of tumors carried more than 10 pathogenic mutations. Despite that the applied reading depth was very high in our cases $(>1000 \mathrm{X}$, compared to $<50 \mathrm{X}$ in whole genome sequencing), the 4 most frequently mutated genes are in line with previous publications. The high incidence of BRCA1, PTEN, CDH1 and BRCA2 mutations is most probably a result of high reading depth and over-representation of these genes in the custom panel. Red dots: genes with site-specific differences in the distribution of pathogenic mutations. (B) Demonstrates the actual number of tumors with pathogenic mutations in the presented genes. The number of tumors with pathogenic mutations is shown for the 15 most frequently affected genes. Blue bars correspond to the number of pathogenic mutations per gene; tumor suppressor genes, e.g., APC, TP53, occasionally carried multiple mutations per tumor, which was not observed for oncogenes, e.g., KRAS, BRAF. (C) Comparison of mutation numbers in MMR-D and MMR-P tumors. Although MMR-D were in general richer in mutations compared to MMR-P tumors, MMR-P tumors with mutations in MMR genes (red dots) exhibited higher mutation numbers compared to MMR-D, probably because of co-mutated pathways. Green dots: four MMR-D tumors with concordant MMR gene mutation status. Blue lines: mean values. 
CRC patients. High density of tumor infiltrating CD8+ lymphocytes, was associated with good prognosis. Pathogenic mutations in BRCA1 and ARID1A were associated with poor outcomes in the patients of our study.

Recently, a lot of interest has focused on the immunogenic profile of colorectal tumors. The prognostic significance of TILs has been clearly shown in many different studies [12-16]. Moreover, published data suggest that the prognostic significance depends on the specific immune cell types that infiltrate the tumor and the tumor area [11]. Here, we evaluated the prognostic effect of cytotoxic T cells assessed by CD8 within the tumor nests and in the stroma. In accordance to our results, CD8+ density has been previously shown to be a major favorable prognostic factor in CRC [17], and has been successfully used in prognostic immunological profiles [10]. However, there are limited data on the association of CD8+ cell density and tumor location. In our study, rightsided tumors were enriched for high CD8+ density, which may be attributed to the higher rates of MMR-D in those tumors and, therefore, increased immunogenicity. Due to the small sample size of MMR-D tumors, these results

\section{A}

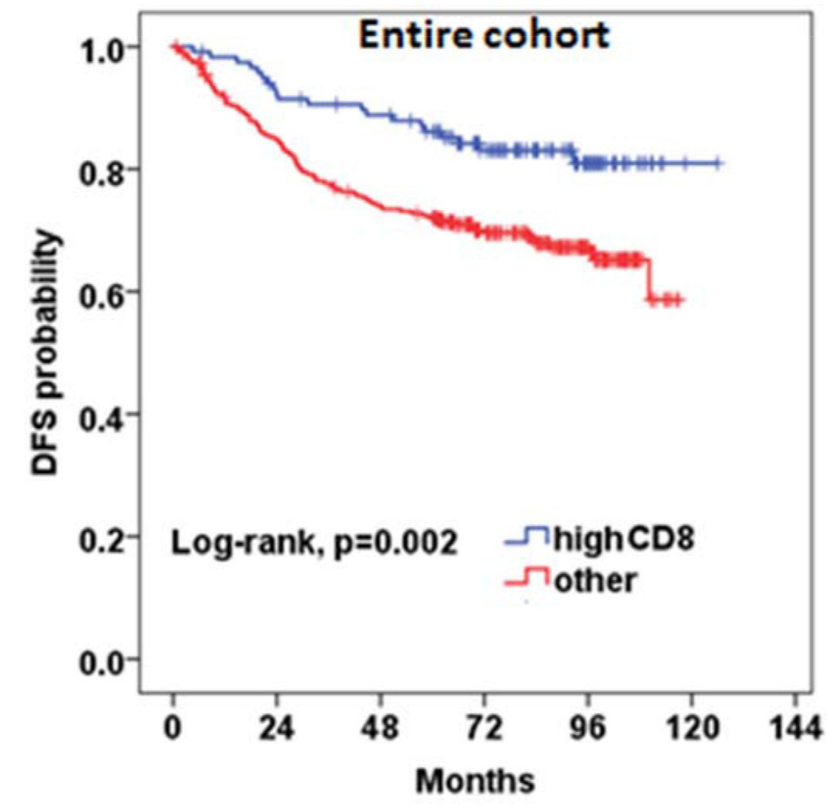

B

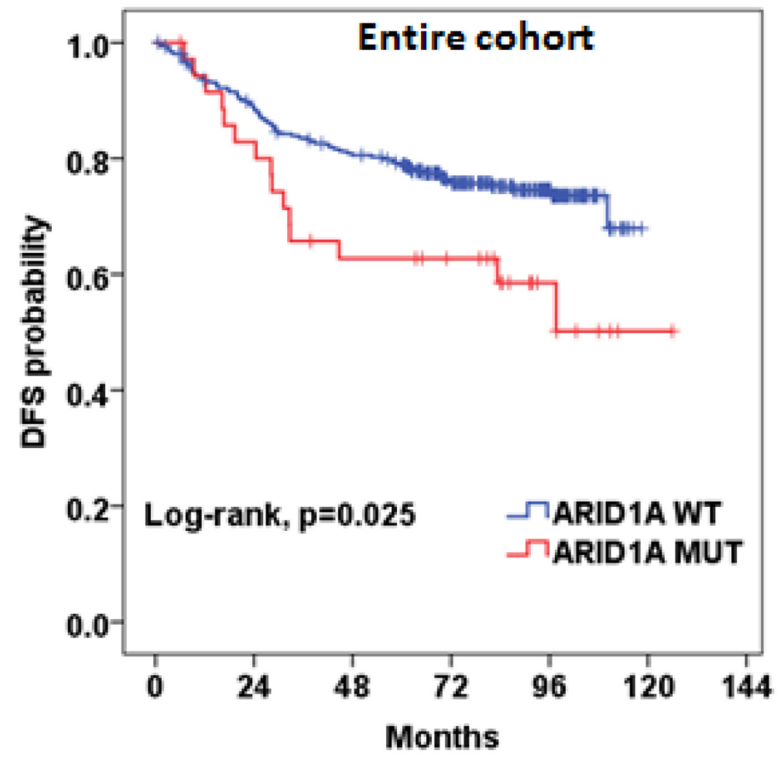

C

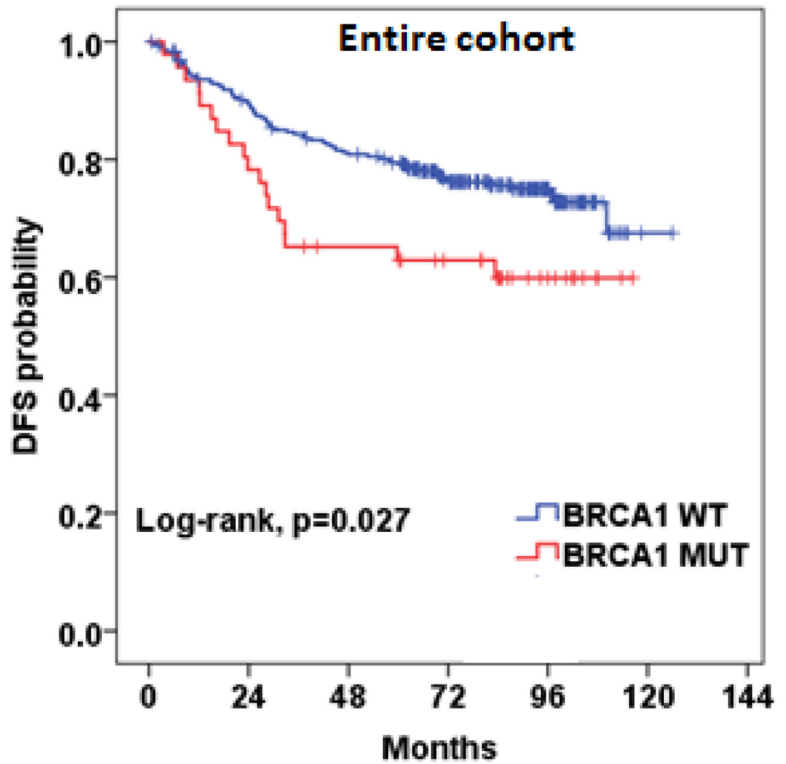

Figure 3: Prognostic significance of (A) high CD8+ density; (B and C) BRCA1 and ARID1A pathogenic mutations. 
need to be addressed with caution. We have previously published an immune response gene expression profile and its stage- and site-specific prognostic implications [18]. A low immune response was associated with inferior DFS only in patients with stage III right colorectal tumors. The novelty of our finding is that the $\mathrm{CD} 8+$ cytotoxic $\mathrm{T}$ cell density can be used as a single marker of good prognosis, independently of tumor compartment, i.e., core or invasive margin, in non-metastatic stage CRC. Since the morphological assessment of TILs is not reliable in CRC [17], using one IHC marker instead of two or more, in sections where the invasive margin is not assessable, will facilitate the integration of immunodiagnostics in stages I-III of this disease.

It is of high importance to map the genomic profile of $\mathrm{CRC}$, to identify potential prognostic markers or even therapeutic targets. In our patient cohort, we noted differences in mutation rates of specific genes depending on tumor location. Left-sided tumors were more likely to harbor TP53 mutations, also noted in another study [19]. Rectal tumors were enriched for FBXW7 mutations compared to the rest of the tumors, which has also been noticed previously $[20,21]$. FBXW7 is a tumor suppressor gene [22], shown to target several proteins implicated in cell division and cell growth, for ubiquitination and subsequent degradation [23-25]. However, the prognostic relevance of rectal FBXW7 mutations remains unclear. Right-sided tumors had a higher frequency of BRAF and PIK3CA mutations compared to left-sided and rectal tumors. Similarly, other investigators showed that right-sided tumors had a higher frequency of PIK3CA mutations [26]. The higher frequency of BRAF mutations has been associated with stage IV right-sided tumors [27]. Emerging data show that BRAF mutations are similarly more frequent in non-metastatic right-sided tumors [2830]. We have also shown that the mere presence of tumor MMR gene mutations is not necessarily accompanied by MMR protein deficiency. This was not unexpected, since both alleles need to become inactivated for protein loss [31]. Unfortunately, no germline data were available in our patients; thus, we cannot provide any information on the inherited status of the observed MLH1, MSH2 and MSH6 mutations, even in the 4 cases with concordant loss of the corresponding protein. Interestingly, compared to MMR-D, these tumors with MMR gene mutations and MMR-P status, were more likely hypermutated, had different clonal pathogenic mutational profiles in POLE (another gene associated with hypermutation [32] and in

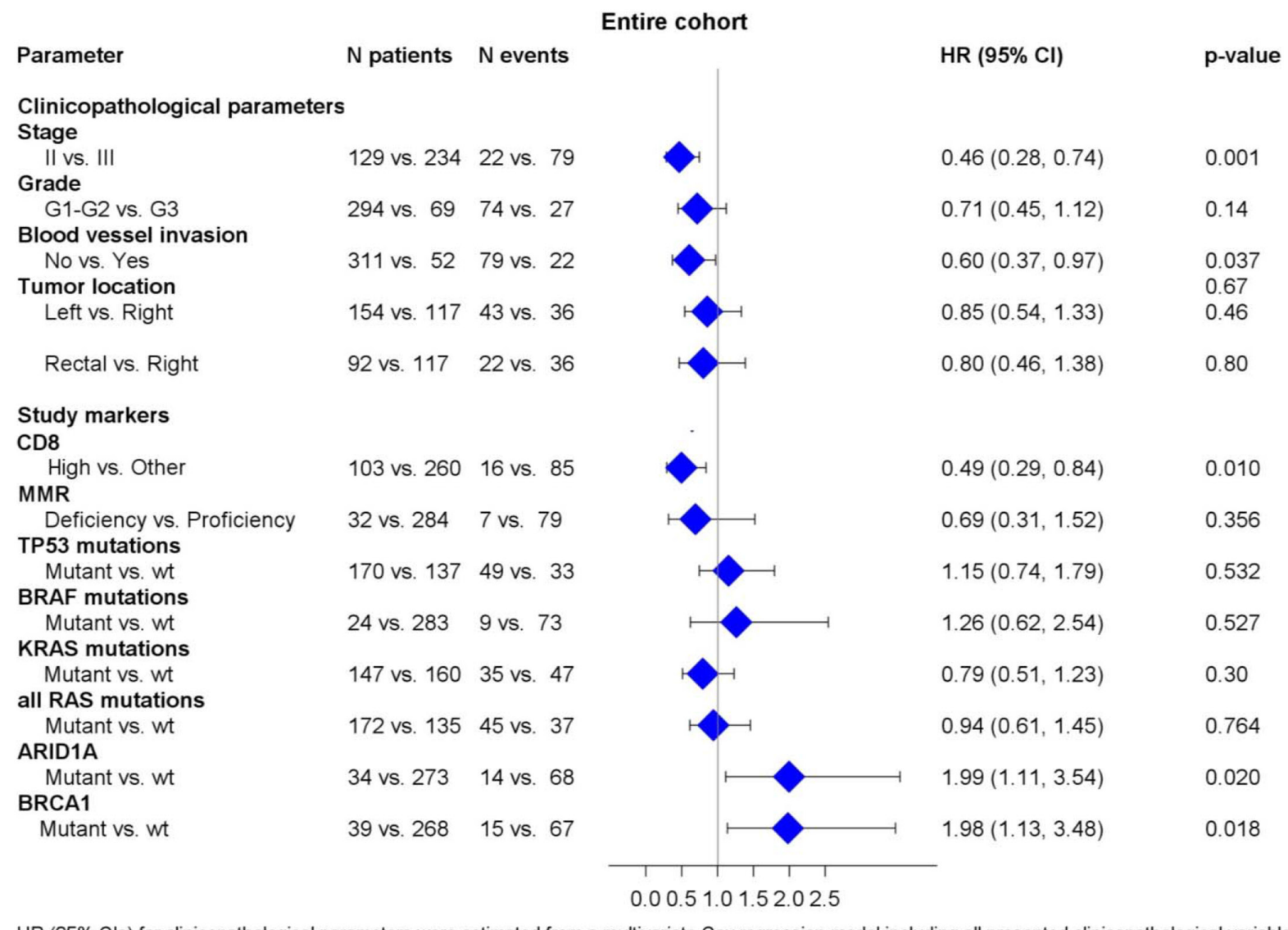

HR $(95 \% \mathrm{Cls})$ for clinicopathological parameters were estimated from a multivariate Cox regression model including all presented clinicopathological variables; HR (95\% Cls) for each marker were adjusted for tumor stage, grade and blood vessel invasion.

Figure 4: Associations between DFS and relevant clinicopathological, mutational and immunophenotypic parameters. 
the RAS/RAF pathway, and, they were primarily located in the left colon. These features are in line with the recently published profiles of gastrointestinal adenocarcinomas [33]. In addition, mutations in genes traditionally regarded as sources of hypermutation may in fact be surrogates for multiple mutational processes operating in a tumor [34]. Clearly, the presented MMR-P \& MMR-mutated phenotype is an exploratory finding in a small number of cases, but it appears worth validating in larger series for comprehending the biology and planning appropriate treatments for these tumors.

BRAF mutations have been extensively studied in CRC, and have been strongly associated with poor outcomes in metastatic tumors [27], particularly with respect to the classical BRAF p.V600E; non-V600E mutations seem to confer favorable prognosis [35], which was indicated in the few such patients in our series as well. In non-metastatictumors, data supporting the prognostic significance of BRAF mutations are not as clear [9, 30, 36-38]. A retrospective analysis of BRAF mutations in prospectively collected tumor blocks from patients enrolled in the PETACC-8 trial demonstrated that the BRAFV600E mutation was not prognostic in the entire cohort [39]. However, subgroup analysis showed that in patients with microsatellite-stable tumors BRAF mutation was independently associated with poor clinical outcomes. Even though BRAF mutational status was not associated with DFS in our cohort, we observed a statistical trend for the association of BRAF mutations with poor prognosis in the subgroup of patients with MMR-P tumors. However, due to the small number of patients with MMR-P/BRAF-mutated tumors (13 patients), we cannot draw definitive conclusions. Another study suggested that the prognostic significance of BRAF mutations depends on the microsatellite instability of the tumor [38]. In contrast, other investigators have shown that the OS between patients with stage I-II CRC with and without BRAF mutations was similar [30]. Further prospective studies are needed to provide robust data on the prognostic significance of BRAF mutations.

We demonstrated that BRCA1 and ARID1A pathogenic mutations were associated with poor DFS in patients with non-metastatic CRC. ARID1A, a tumor suppressor gene, has been suggested as the most commonly deregulated ATP-dependent chromatin remodeler [40]. Studies suggest that loss of ARID1A expression is associated with poor differentiation, higher stage, distant metastasis [41] and lymphovascular invasion [42]. However, the prognostic significance of ARID1A in colorectal cancer has yet to be determined. Other studies supported the prognostic significance of BRCA1 in colorectal cancer. In a retrospective study, loss of heterozygosity (LOH) in the BRCA1 locus was associated with decreased DFS and OS [43]. In another study, high expression of BRCA1 cytoplasmic expression was associated with favorable OS in digestive system cancers [44]. Our findings are in line with these studies. Of note, mutations in these genes were mostly represented at subclonal frequencies within the affected tumors, while LOH, which would imply loss of gene function, was inferred in only $9 \%$ of BRCA1 and in $19 \%$ of ARID1A mutated tumors. These features and the respective higher mutational burden may suggest that BRCA1 and ARID1A mutations be surrogates for underlying mutational processes that affect CRC behavior [32]. Nevertheless, due to the exploratory nature of our study, these results are hypothesis generating and need to be compared with corresponding deep sequencing results from large patient series and prospectively tested for their clinical value.

Tumor location was not an independent prognostic factor in our patient cohort. Data regarding the independent prognostic significance of tumor location in non-metastatic CRC are conflicting [45-48]. In a retrospective study of 6,365 patients with stage I to III colon cancer, there was no difference in overall and cancer-specific survival between patients with right and left-sided tumors [47]. Population analysis of 91,416 patients with colon cancer demonstrated that compared to left-sided tumors, right-sided colon tumors had significantly increased cancer-specific survival in localized disease (stage I and II) [48]. Cancer-specific survival was equivalent between patients with right- and left-sided tumors in regional disease (stage III). These contradictory data underline the importance of identifying prognostic biomarkers which drive the disparate disease outcomes of patients with stage I - III disease, irrespectively of tumor location.

Our work has certain limitations. First, its retrospective design. Second, our study included patients with stages I to III. Even though we adjusted for stage, there might be molecular differences associated with more advanced disease, which might have confounded our analysis. Third, our NGS panel targeted 59 genes only; therefore, we could not accurately distinguish tumors into hypermutated and non-hypermutated. Finally, the sample size of the study did not allow for assessing the possible prognostic role of genes less frequently mutated.

In conclusion, colorectal tumors have complex clinicopathological, mutational and immunophenotypic profiles. CD8+ density, BRCA1 and ARID1A mutations were shown to be independently associated with DFS in our patient cohort.

CD8+ IHC may be developed as a single marker for integration in routine diagnostics. The clinical impact of these biomarkers, if further validated, may aid in the accurate prognostic stratification of non-metastatic CRC patients. Further studies are needed to comprehend the underlying biological heterogeneity of colorectal tumors and personalize patient management. 


\section{MATERIALS AND METHODS}

\section{Patients and tissues}

We retrospectively assessed patients with primary colorectal adenocarcinomas, diagnosed between March 2007 and September 2012, treated in Academic Institutions and private clinics affiliated with the Hellenic Cooperative Oncology Group (HeCOG). Patients were diagnosed with non-metastatic disease (stages I - III) and were followed for at least five years. All patients underwent surgical resection of their primary tumor and then received adjuvant treatment, if needed, depending on clinical and histopathological risk factors. Adjuvant chemotherapy comprised of oxaliplatin, leucovorin and 5-fluoruracil administered intravenously (FOLFOX) or oral capecitabine combined with oxaliplatin administered intravenously (CAPOX). Patients with rectal cancer received adjuvant treatment with chemotherapy and/ or radiation therapy, based on the treating physician's judgment. We retrieved patient clinical demographics, tumor histopathological and treatment data from the patients' medical records. Signed informed consent was obtained from all patients for the use of their biologic material for research purposes. The translational protocol was conducted in agreement with the Declaration of Helsinki and was approved by the Institutional Review Boards of "Papageorgiou" Hospital (1338/12-1-2015) and "Thermi" Clinic (307/2-3-2016).

Formalin-Fixed Paraffin-Embedded (FFPE) tissues were retrieved from the $\mathrm{HeCOG}$ repository. Central tumor histology review, tissue processing, immunophenotyping and targeted next generation sequencing (NGS) genotyping were performed in the Laboratory of Molecular Oncology (Hellenic Foundation for Cancer Research/Aristotle University of Thessaloniki). We constructed 34 lowdensity tissue microarrays (TMAs) with multiple $1 \mathrm{~mm}$ cores per tumor (range per tumor: 3 - 10 cores). Cores from the tumor center were available in 281 and from the tumor front (invasive margin) in 285 tumors ( $\geq 4$ cores in these cases). No distinction between center and front was possible in 132 cases ( 3 cores per tumor in these cases). TMAs were used for the application of IHC and NGS. As described in Figure 1, we examined 412 tumors from an equal number of patients.

\section{IHC methods and interpretation}

We performed IHC for CD8+ and MMR proteins (MLH1, PMS2, MSH2, MSH6) on 3 $\mu \mathrm{m}$ TMA sections (method details in Supplementary Methods).

We evaluated intratumoral (i-CD8+) and stromal $\mathrm{CD} 8+(\mathrm{s}-\mathrm{CD} 8+)$ tumor-infiltrating lymphocyte (TIL) density. i-CD8+ cells were those in direct contact to cancer cells within neoplastic nests. We assessed s-CD8+ cells as area percentage of the entire stromal area by counting
CD8+ cells in all medium power fields (magnification $\mathrm{X} 100$ ) on all available TMA cores per tumor, and i-CD8+ cells as percentage of all cells within cancer nests in each of high power field (HPF, magnification X400); i-CD8+ counts were obtained from at least 8 HPFs for tumor core and similarly for tumor front, and from more than 10 HPFs in the cases where compartment distinction was not available. For each tumor, we processed the maximal counts per variable [49], initially for tumor center (278 informative tumors with 2 cores per compartment) and tumor front (276 informative tumors). The distribution of the obtained values between tumor center and front did not vary, as shown in Supplementary Figure 2. Based on this observation, we merged center and front values, again by using the maximal value per paired counts. Based on the distribution of the merged values (Supplementary Figure 2 ), we categorized (a) s-CD8+ as high $(\geq 15 \%)$ and low $(<15 \%)$, and (b) i-CD $8+$ as high $(\geq 2 \%)$ and low $(0-1 \%)$.

We then combined these two variables into i-\&sCD8 with initially 4 Cartesian categories (both high, both low, i-high/s-low, i-low/s-high). Because there were only 29 tumors with i-high/s-low (7\% of the cohort) which would compromise statistical analysis, and also because we did not observe any difference in the outcome of patients with i-low/s-high $(\mathrm{N}=106$ [25.7\%]) and both low $(\mathrm{N}=159$ [38.6\%]), we next merged these $4 \mathrm{i}-\& \mathrm{~s}-\mathrm{CD} 8+$ categories into both high $(\mathrm{N}=118$ [28.6\%]) and all other. The "both high" category corresponded to high density CD8+ cytotoxic T cells in the stroma and in direct contact with cancer cells. The "other" category included high CD8+ density only in the stroma or only among cancer cells or low values in these two compartments.

For the four MMR proteins, intensity and percentage were recorded; markers were evaluated in comparison to internal controls (stromal and endothelial cells, lymphocytes) as: positive, if $\geq 10 \%$ positive nuclei with mild to strong intensity were counted; negative, if internal controls were positive and tumor cells were completely negative or exhibited any staining $<10 \%$; non-informative, if tumor cells were negative and internal controls were negative (assay failure; biallelic loss of the particular protein could not be considered). Tumor MMR status was evaluated if informative results for all four MMR proteins were available. Tumors with negative result in one of the four proteins were classified as MMR deficient [50].

\section{NGS genotyping and mutation characterization}

Method details are provided in Supplementary Methods. Briefly, DNA was extracted from TMA core sections, quality assessed, and submitted for semiconductor sequencing with a custom Ampliseq panel (Thermo - Fisher Scientific, Paisley, UK). Panel targets are shown in Supplementary Table 8. Upon very stringent filtering for minimizing false positive variants, we obtained informative results for 347 out of 404 
sequenced tumors. Informative tumors were read at very high depth (median and mean values of mean depth were 1284 and 1659, respectively; technical characteristics and variant distribution are shown in Supplementary Figure 3). Amino acid or splice site changing variants with minor allele frequency $<0.1 \%$ were called mutations. Based on the obtained mutation frequencies (VAFs), functions and genotypes (Supplementary Figure 4), we analysed only pathogenic or likely pathogenic mutations according to FATHMM, ClinVar and COSMIC. We also assessed mutation clonality based on VAFs compared to tumor cell content (details in Supplementary Methods).

\section{Statistical analysis}

Possible associations between two categorical variables were assessed with the chi-square test. The Mann-Whitney or Kruskal-Wallis tests were used for comparing the values of a continuous variable across the levels of a categorical variable. The primary endpoint was DFS, defined as the time from the date of diagnosis to documented first relapse, death or last contact, whichever occurred first. Surviving patients were censored at the date of last contact. Survival curves were estimated using the Kaplan-Meier method and compared across groups with the log-rank test. The associations between the factors examined and relapse rates were evaluated with hazard ratios, estimated with Cox proportional hazards model. In multivariate analyses, we estimated the effect (HR) of IHC and NGS parameters adjusted for the effect of clinical factors which were univariately associated with DFS. Cox regression analyses including an interaction term between tumor location and selected IHC/NGS parameters were also performed in order to identify factors that differentiated the effect of tumor location on DFS. Because this study was exploratory with predefined parameters, we did not apply correction for multiple testing, based on Feise et al [51].

The statistical analyses were performed using the SAS software (SAS for Windows, version 9.4, SAS Institute Inc., Cary, NC). Statistical significance was set at a 2 -sided $\mathrm{p}=0.05$.

\section{Abbreviations}

CAPOX: capecitabine and oxaliplatin; CI: confidence interval; CRC: colorectal cancer; DFS: disease-free survival; FFPE: Formalin-Fixed ParaffinEmbedded; FOLFOX: oxaliplatin, leucovorin and 5-fluoruracil; HeCOG: Hellenic Cooperative Oncology Group; IHC: immunohistochemistry; HPF: high power field; HR: hazard ratio; i-CD8: intratumoral CD8; LVI: lymphovascular invasion; MMR: mismatch repair; MMR-D: MMR deficient; MMR-P: MMR proficient; $\mathrm{N}$ : number; NGS: next generation sequencing; OS: overall survival; PNI: perineural invasion; s-CD8: stromal
CD8; SD: standard deviation; TIL: tumor-infiltrating lymphocyte; TMA: tissue microarray; VAF: variant allele frequency.

\section{Author contributions}

EF: Study conception and design, clinical data management, bioinformatics analysis, data analysis, results interpretation, manuscript writing; VK: Method design and supervision of implementation, bioinformatics analysis, IHC data analysis, results interpretation, manuscript writing; IT: Bioinformatics analysis; KM, GAK: Clinical data management, biostatistics; KP: NGS experiments; CP: Histology review, TMA construction, IHC evaluation; VK, DP, IV, CC, GPa, GKG, AP, GA: Provision of patients; IE, KIP, GKK: provision of tumor material; SC: IHC stains, tissue block management; GEP: study conception and design, provision of patients; GF: study conception and design, provision of patients, clinical data management and supervision; administrative and financial support. All authors reviewed the manuscript and approved the final version.

\section{ACKNOWLEDGMENTS}

The authors are indebted to all patients and their families for their trust and participation in the clinical part of the study as well as for the provision of biological material for research purposes.

The authors wish to thank Emily Daskalaki for excellent technical assistance with NGS, Helen Sgouramalli, MSc for block sectioning and Maria Moschoni for data coordination.

\section{CONFLICTS OF INTEREST}

The authors declare no conflicts of interest.

\section{FUNDING}

The study was supported by a research grant from Astra-Zeneca (ESR-15-10766) and by an internal Hellenic Cooperative Oncology Group (HeCOG) translational research grant (HER_6C/08).

Dr. E. Fountzilas has received a scholarship from the Hellenic Society of Medical Oncology (10/2017-09/2018).

\section{REFERENCES}

1. The Cancer Genome Atlas Network. Comprehensive molecular characterization of human colon and rectal cancer. Nature. 2012; 487:330-37.

2. Guinney J, Dienstmann R, Wang X, de Reyniès A, Schlicker A, Soneson C, Marisa L, Roepman P, Nyamundanda G, Angelino P, Bot BM, Morris JS, Simon IM, et al. The 
consensus molecular subtypes of colorectal cancer. Nat Med. 2015; 21:1350-56.

3. Karapetis CS, Khambata-Ford S, Jonker DJ, O'Callaghan CJ, Tu D, Tebbutt NC, Simes RJ, Chalchal H, Shapiro JD, Robitaille S, Price TJ, Shepherd L, Au HJ, et al. $\mathrm{K}$-ras mutations and benefit from cetuximab in advanced colorectal cancer. N Engl J Med. 2008; 359:1757-65.

4. De Roock W, Claes B, Bernasconi D, De Schutter J, Biesmans B, Fountzilas G, Kalogeras KT, Kotoula V, Papamichael D, Laurent-Puig P, Penault-Llorca F, Rougier P, Vincenzi B, et al. Effects of KRAS, BRAF, NRAS, and PIK3CA mutations on the efficacy of cetuximab plus chemotherapy in chemotherapy-refractory metastatic colorectal cancer: a retrospective consortium analysis. Lancet Oncol. 2010; 11:753-62.

5. Yokota T, Ura T, Shibata N, Takahari D, Shitara K, Nomura M, Kondo C, Mizota A, Utsunomiya S, Muro K, Yatabe Y. BRAF mutation is a powerful prognostic factor in advanced and recurrent colorectal cancer. $\mathrm{Br} \mathrm{J}$ Cancer. 2011; 104:856-62.

6. Yoon HH, Tougeron D, Shi Q, Alberts SR, Mahoney MR, Nelson GD, Nair SG, Thibodeau SN, Goldberg RM, Sargent DJ, Sinicrope FA, and Alliance for Clinical Trials in Oncology. KRAS codon 12 and 13 mutations in relation to disease-free survival in BRAF-wild-type stage III colon cancers from an adjuvant chemotherapy trial (N0147 alliance). Clin Cancer Res. 2014; 20:3033-43.

7. Ogino S, Shima K, Meyerhardt JA, McCleary NJ, Ng K, Hollis D, Saltz LB, Mayer RJ, Schaefer P, Whittom R, Hantel A, Benson AB 3rd, Spiegelman D, et al. Predictive and prognostic roles of BRAF mutation in stage III colon cancer: results from intergroup trial CALGB 89803. Clin Cancer Res. 2012; 18:890-900.

8. Sinicrope FA, Mahoney MR, Smyrk TC, Thibodeau SN, Warren RS, Bertagnolli MM, Nelson GD, Goldberg RM, Sargent DJ, Alberts SR. Prognostic impact of deficient DNA mismatch repair in patients with stage III colon cancer from a randomized trial of FOLFOX-based adjuvant chemotherapy. J Clin Oncol. 2013; 31:3664-72.

9. Taieb J, Zaanan A, Le Malicot K, Julié C, Blons H, Mineur L, Bennouna J, Tabernero J, Mini E, Folprecht G, Van Laethem JL, Lepage C, Emile JF, Laurent-Puig P. Prognostic effect of BRAF and KRAS mutations in patients with stage III colon cancer treated with leucovorin, fluorouracil, and oxaliplatin with or without cetuximab: A post hoc analysis of the PETACC-8 trial. JAMA Oncol. 2016; 2:643-653.

10. Galon J, Costes A, Sanchez-Cabo F, Kirilovsky A, Mlecnik $B$, Lagorce-Pagès $C$, Tosolini $M$, Camus $M$, Berger A, Wind $\mathrm{P}$, Zinzindohoué F, Bruneval $\mathrm{P}$, Cugnenc $\mathrm{PH}$, et al. Type, density, and location of immune cells within human colorectal tumors predict clinical outcome. Science. 2006; 313:1960-64.

11. Mei Z, Liu Y, Liu C, Cui A, Liang Z, Wang G, Peng H, Cui $\mathrm{L}, \mathrm{Li}$ C. Tumour-infiltrating inflammation and prognosis in colorectal cancer: systematic review and meta-analysis. $\mathrm{Br}$ J Cancer. 2014; 110:1595-605.

12. Nizri E, Greenman-Maaravi N, Bar-David S, Ben-Yehuda A, Weiner G, Lahat G, Klausner J. Analysis of histological and immunological parameters of metastatic lymph nodes from colon cancer patients reveals that T-helper 1 type immune response is associated with improved overall survival. Medicine (Baltimore). 2016; 95:e5340.

13. Yoon HH, Orrock JM, Foster NR, Sargent DJ, Smyrk TC, Sinicrope FA. Prognostic impact of FoxP3+ regulatory T cells in relation to CD8+ T lymphocyte density in human colon carcinomas. PLoS One. 2012; 7:e42274.

14. Chew A, Salama P, Robbshaw A, Klopcic B, Zeps N, Platell C, Lawrance IC. SPARC, FOXP3, CD8 and CD45 correlation with disease recurrence and long-term diseasefree survival in colorectal cancer. PLoS One. 2011; 6:e22047.

15. Berntsson J, Svensson MC, Leandersson K, Nodin B, Micke P, Larsson AH, Eberhard J, Jirström K. The clinical impact of tumour-infiltrating lymphocytes in colorectal cancer differs by anatomical subsite: A cohort study. Int J Cancer. 2017; 141:1654-66.

16. Allen WL, Dunne PD, McDade S, Scanlon E, Loughrey M, Coleman H, McCann C, McLaughlin K, Nemeth Z, Syed N, Jithesh P, Arthur K, Wilson R, et al. Transcriptional subtyping and cd8 immunohistochemistry identifies patients with stage II/III colorectal cancer with poor prognosis who benefit from adjuvant chemotherapy. JCO Precis Oncol. 2018; 2018.

17. Fridman WH, Zitvogel L, Sautès-Fridman C, Kroemer G. The immune contexture in cancer prognosis and treatment. Nat Rev Clin Oncol. 2017; 14:717-34.

18. Pentheroudakis G, Raptou G, Kotoula V, Wirtz RM, Vrettou E, Karavasilis V, Gourgioti G, Gakou C, Syrigos KN, Bournakis E, Rallis G, Varthalitis I, Galani E, et al. Immune response gene expression in colorectal cancer carries distinct prognostic implications according to tissue, stage and site: a prospective retrospective translational study in the context of a hellenic cooperative oncology group randomised trial. PLoS One. 2015; 10:e0124612.

19. Takahashi Y, Sugai T, Habano W, Ishida K, Eizuka M, Otsuka K, Sasaki A, Matsumoto T, Morikawa T, Unno M, Suzuki H. Molecular differences in the microsatellite stable phenotype between left-sided and right-sided colorectal cancer. Int J Cancer. 2016; 139:2493-501.

20. Bai J, Gao J, Mao Z, Wang J, Li J, Li W, Lei Y, Li S, Wu Z, Tang C, Jones L, Ye H, Lou F, et al. Genetic mutations in human rectal cancers detected by targeted sequencing. $\mathrm{J}$ Hum Genet. 2015; 60:589-96.

21. Crumley SM, Pepper KL, Phan AT, Olsen RJ, Schwartz MR, Portier BP. Next-generation sequencing of matched primary and metastatic rectal adenocarcinomas demonstrates minimal mutation gain and concordance to colonic adenocarcinomas. Arch Pathol Lab Med. 2016; 140:529-35. 
22. Akhoondi S, Sun D, von der Lehr N, Apostolidou S, Klotz K, Maljukova A, Cepeda D, Fiegl H, Dafou D, Marth C, Mueller-Holzner E, Corcoran M, Dagnell M, et al. FBXW7/ hCDC4 is a general tumor suppressor in human cancer. Cancer Res. 2007; 67:9006-12.

23. Welcker M, Clurman BE. FBW7 ubiquitin ligase: a tumour suppressor at the crossroads of cell division, growth and differentiation. Nat Rev Cancer. 2008; 8:83-93.

24. Mao JH, Kim IJ, Wu D, Climent J, Kang HC, DelRosario R, Balmain A. FBXW7 targets mTOR for degradation and cooperates with PTEN in tumor suppression. Science. 2008; 321:1499-502.

25. Kwon YW, Kim IJ, Wu D, Lu J, Stock WA Jr, Liu Y, Huang Y, Kang HC, DelRosario R, Jen KY, Perez-Losada J, Wei G, Balmain A, Mao JH. Pten regulates Aurora-A and cooperates with Fbxw7 in modulating radiation-induced tumor development. Mol Cancer Res. 2012; 10:834-44.

26. Salem ME, Weinberg BA, Xiu J, El-Deiry WS, Hwang JJ, Gatalica Z, Philip PA, Shields AF, Lenz HJ, Marshall JL. Comparative molecular analyses of left-sided colon, rightsided colon, and rectal cancers. Oncotarget. 2017; 8:8635668. https://doi.org/10.18632/oncotarget.21169.

27. Tol J, Nagtegaal ID, Punt CJ. BRAF mutation in metastatic colorectal cancer. N Engl J Med. 2009; 361:98-99.

28. Yamauchi M, Morikawa $T$, Kuchiba A, Imamura $Y$, Qian ZR, Nishihara R, Liao X, Waldron L, Hoshida Y, Huttenhower C, Chan AT, Giovannucci E, Fuchs C, Ogino $\mathrm{S}$. Assessment of colorectal cancer molecular features along bowel subsites challenges the conception of distinct dichotomy of proximal versus distal colorectum. Gut. 2012; 61:847-54.

29. Minoo P, Zlobec I, Peterson M, Terracciano L, Lugli A. Characterization of rectal, proximal and distal colon cancers based on clinicopathological, molecular and protein profiles. Int J Oncol. 2010; 37:707-18.

30. Chen KH, Lin YL, Liau JY, Tsai JH, Tseng LH, Lin LI, Liang JT, Lin BR, Hung JS, Chang YL, Yeh KH, Cheng AL. BRAF mutation may have different prognostic implications in early- and late-stage colorectal cancer. Med Oncol. 2016; 33:39.

31. Patel SA, Longacre TA, Ladabaum U, Lebensohn A, Lin AY, Haraldsdottir S. Tumor molecular testing guides anti-PD-1 therapy and provides evidence for pathogenicity of mismatch repair variants. Oncologist. 2018 Aug 2. [Epub ahead of print].

32. Knijnenburg TA, Wang L, Zimmermann MT, Chambwe N, Gao GF, Cherniack AD, Fan H, Shen H, Way GP, Greene CS, Liu Y, Akbani R, Feng B, et al. Genomic and molecular landscape of DNA damage repair deficiency across The Cancer Genome Atlas. Cell Rep. 2018; 23:239-254.e6.

33. Liu Y, Sethi NS, Hinoue T, Schneider BG, Cherniack AD, Sanchez-Vega F, Seoane JA, Farshidfar F, Bowlby R, Islam M, Kim J, Chatila W, Akbani R, et al. Comparative molecular analysis of gastrointestinal adenocarcinomas. Cancer Cell. 2018; 33:721-735.e8.
34. Sanchez-Vega F, Mina M, Armenia J, Chatila WK, Luna A, La KC, Dimitriadoy S, Liu DL, Kantheti HS, Saghafinia S, Chakravarty D, Daian F, Gao Q, et al. Oncogenic signaling pathways in The Cancer Genome Atlas. Cell. 2018; 173:321-337.e10.

35. Jones JC, Renfro LA, Al-Shamsi HO, Schrock AB, Rankin A, Zhang BY, Kasi PM, Voss JS, Leal AD, Sun J, Ross J, Ali SM, Hubbard JM, et al. Non-V600 BRAF mutations define a clinically distinct molecular subtype of metastatic colorectal cancer. J Clin Oncol. 2017; 35:2624-30.

36. Zhu L, Dong C, Cao Y, Fang X, Zhong C, Li D, Yuan Y. Prognostic role of BRAF mutation in stage II/III colorectal cancer receiving curative resection and adjuvant chemotherapy: A meta-analysis based on randomized clinical trials. PLoS One. 2016; 11:e0154795.

37. Sayagués JM, Del Carmen S, Del Mar Abad M, Corchete LA, Bengoechea O, Anduaga MF, Baldeón MJ, Cruz JJ, Alcazar JA, Angoso M, González M, García J, MuñozBellvis L, et al. Combined assessment of the TNM stage and BRAF mutational status at diagnosis in sporadic colorectal cancer patients. Oncotarget. 2018; 9:24081-96. https://doi.org/10.18632/oncotarget.25300.

38. Punt CJ, Koopman M, Vermeulen L. From tumour heterogeneity to advances in precision treatment of colorectal cancer. Nat Rev Clin Oncol. 2017; 14:235-46.

39. Taieb J, Kourie HR, Emile JF, Le Malicot K, Balogoun R, Tabernero J, Mini E, Folprecht G, Van Laethem JL, Mulot C, Bouche O, Aparicio T, Michel P, et al; PanEuropean Trials in Alimentary Tract Cancer (PETACC)-8 Investigators. Association of prognostic value of primary tumor location in stage III colon cancer with RAS and BRAF mutational status. JAMA Oncol. 2018; 4:e173695.

40. Wu RC, Wang TL, Shih IM. The emerging roles of ARID1A in tumor suppression. Cancer Biol Ther. 2014; 15:655-64.

41. Wei XL, Wang DS, Xi SY, Wu WJ, Chen DL, Zeng ZL, Wang RY, Huang YX, Jin Y, Wang F, Qiu MZ, Luo HY, Zhang DS, $\mathrm{Xu} \mathrm{RH}$. Clinicopathologic and prognostic relevance of ARID1A protein loss in colorectal cancer. World J Gastroenterol. 2014; 20:18404-18412.

42. Lee LH, Sadot E, Ivelja S, Vakiani E, Hechtman JF, Sevinsky CJ, Klimstra DS, Ginty F, Shia J. ARID1A expression in early stage colorectal adenocarcinoma: An exploration of its prognostic significance. Hum Pathol. 2016; 53:97-104.

43. Garcia JM, Rodriguez R, Dominguez G, Silva JM, Provencio M, Silva J, Colmenarejo A, Millan I, Muñoz C, Salas C, Coca S, España P, Bonilla F. Prognostic significance of the allelic loss of the BRCA1 gene in colorectal cancer. Gut. 2003; 52:1756-63.

44. Wang GH, Zhao CM, Huang Y, Wang W, Zhang S, Wang $\mathrm{X}$. BRCA1 and BRCA2 expression patterns and prognostic significance in digestive system cancers. Hum Pathol. 2018; 71:135-144.

45. Kennecke HF, Speers C, Davies JM, Cheung WY, Lee-Ying RM. Differences in relapse-free survival (RFS) and survival 
after relapse (SAR) in right (R) versus left (L) stage I-III colon cancer (CCa). Journal of Clinical Oncology. 2016; 34:3578-3578.

46. Lara JF, Thor AD, Dressler LG, Broadwater G, Bleiweiss IJ, Edgerton S, Cowan D, Goldstein LJ, Martino S, Ingle JN, Henderson IC, Norton L, Winer EP, et al; Cancer and Leukemia Group B. p53 Expression in node-positive breast cancer patients: results from the Cancer and Leukemia Group B 9344 Trial (159905). Clin Cancer Res. 2011;17:5170-8.

47. Karim S, Brennan K, Nanji S, Berry SR, Booth CM. Association between prognosis and tumor laterality in early-stage colon cancer. JAMA Oncol. 2017; 3:1386-92.

48. Warschkow R, Sulz MC, Marti L, Tarantino I, Schmied BM, Cerny T, Guller U. Better survival in right-sided versus left-sided stage I - III colon cancer patients. BMC Cancer 2016; 16:554.
49. Goode EL, Block MS, Kalli KR, Vierkant RA, Chen W, Fogarty ZC, Gentry-Maharaj A, Tołoczko A, Hein A, Bouligny AL, Jensen A, Osorio A, Hartkopf A, et al, and Ovarian Tumor Tissue Analysis (OTTA) Consortium. Doseresponse association of $\mathrm{cd} 8+$ tumor-infiltrating lymphocytes and survival time in high-grade serous ovarian cancer. JAMA Oncol. 2017; 3:e173290.

50. Pectasides D, Karavasilis V, Papaxoinis G, Gourgioti G, Makatsoris T, Raptou G, Vrettou E, Sgouros J, Samantas E, Basdanis G, Papakostas P, Bafaloukos D, Kotoula V, et al. Randomized phase III clinical trial comparing the combination of capecitabine and oxaliplatin (CAPOX) with the combination of 5-fluorouracil, leucovorin and oxaliplatin (modified FOLFOX6) as adjuvant therapy in patients with operated high-risk stage II or stage III colorectal cancer. BMC Cancer. 2015; 15:384.

51. Feise RJ. Do multiple outcome measures require p-value adjustment? BMC Med Res Methodol. 2002; 2:8. 